\title{
EMERGÊNCIA E DESENVOLVIMENTO INICIAL DA BACABEIRA EM DIFERENTES SUBSTRATOS E AMBIENTES
}

\author{
Nouglas Veloso Barbosa Mendes ${ }^{1 *}$, Denise de Castro Lima ${ }^{2}$, Márcio Cleber de Medeiros Corrêa ${ }^{3}$, \\ William Natale ${ }^{4}$
}

\begin{abstract}
RESUMO - A bacabeira (Oenocarpus bacaba Mart.) é uma palmeira nativa da Amazônia e dispersa pelo norte do Brasil. A germinação das sementes de palmeiras é relativamente lenta e desuniforme, sendo de grande importância pesquisas que avaliem o potencial germinativo da espécie. Objetivou-se avaliar o efeito de diferentes substratos e ambientes na emergência e no desenvolvimento inicial da bacabeira. $O$ delineamento experimental utilizado foi inteiramente ao acaso, com os tratamentos distribuídos em esquema fatorial $5 \times 2$, sendo os fatores, substratos: $\mathrm{S} 1=$ fibra de coco, $\mathrm{S} 2$ = húmus de minhoca, $\mathrm{S} 3$ = fibra de coco + húmus de minhoca $(1: 1 \mathrm{v} / \mathrm{v}), \mathrm{S} 4=$ vermiculita e S5 = bagana de carnaúba; os ambientes: A1 = casa de vegetação e A2 = sombreado, com quatro repetições de 50 sementes por parcela. Determinou-se a emergência, o índice de velocidade de emergência, o tempo médio de emergência, o comprimento da parte aérea e da raiz principal e a massa seca da parte aérea e das raízes. Verificou-se que os substratos húmus de minhoca e vermiculita, são os mais indicados para a emergência e o desenvolvimento inicial da bacabeira. $\mathrm{O}$ ambiente casa de vegetação é o mais indicado para a propagação e desenvolvimento inicial da bacabeira.
\end{abstract}

Palavras chave: Frutífera tropical, Oenocarpus bacaba Mart., palmeira nativa.

\section{EMERGENCE AND INITIAL DEVELOPMENT OF BACABEIRA IN DIFFERENT SUBSTRATES AND ENVIRONMENTS}

\begin{abstract}
The bacabeira (Oenocarpus bacaba Mart.) is a palm tree native from the Brazilian Amazon and dispersed throughout northern Brazil. The germination of the palm seeds is relatively slow and uneven, being extremely important to conduct studies that evaluate the species germination potential. This work aimed to evaluate the effect of different substrates and environments on the bacabeira emergence and initial development. The experimental design was completely randomized, one with the distribution of treatments in the factorial scheme of a $5 \times 2$, which the factors were, for substrates: S1 = coconut fiber, S2 = earthworm humus, S3 = earthworm humus + coconut fiber $(1: 1 \mathrm{v} / \mathrm{v}), S 4=$ vermiculite and $S 5$ = carnauba agroindustrial residue; and for environments: $A 1=$ house of vegetation and $A 2=$ under shade, with four replications of 50 seeds per experimental unit each were used. The emergence, emergence speed index, the mean time of emergence, the length of the aerial part and the main root, and the dry mass of the aerial part and of the roots were determined. It has been found that substrates earthworm humus and vermiculite are the most suitable for emergence and initial development of the bacabeira, and the environment house of vegetation is the most suitable for the initial propagation and development of the bacabeira.
\end{abstract}

Keywords: native palm tree, Oenocarpus bacaba Mart., tropical fruit species.

\footnotetext{
${ }^{1}$ Mestrando em Agronomia-Fitotecnia, Departamento de Fitotecnia, Universidade Federal do Ceará, Fortaleza, CE, Brasil, Av. Mister Hull, 2977, Campus do Pici, Bloco 805; nouglasmendes@hotmail.com *(autor para correspondência)

${ }^{2}$ Doutoranda em Ciência do Solo, Departamento de Ciência do Solo, Universidade Federal do Ceará, Fortaleza, CE, Brasil, Av. Mister Hull, 2977, Campus do Pici, Bloco 807; dennisedecastro@gmail.com

${ }^{3}$ Professor da Graduação e da Pós-graduação, Departamento de Fitotecnia, Universidade Federal do Ceará, Fortaleza, CE, Brasil, Av. Mister Hull, 2977, Campus do Pici, Bloco 805; mcleber@ufc.br

${ }^{4}$ Professor Visitante Sênior, Departamento de Fitotecnia, Universidade Federal do Ceará, Fortaleza, CE, Brasil, Av. Mister Hull,2977, Campus do Pici, Bloco 805; natale@ufc.br
} 


\section{INTRODUÇÃO}

A bacabeira (Oenocarpus bacaba Mart.) é uma palmeira nativa da Amazônia e dispersa pelo norte do Brasil; apresenta estipe reto e solitário, sem espinhos, podendo atingir até $20 \mathrm{~m}$ de altura. $\mathrm{O}$ fruto é arredondado, o epicarpo é verde quando imaturo e roxo tendendo ao preto quando maduro; o mesocarpo é brancacento, sendo dele extraído o "vinho de bacaba" de sabor agradável, cor creme e com alto teor de óleo; o endocarpo é delgado fibroso e envolve a amêndoa (Cavalcante, 2010). A bacabeira é bastante utilizada na confecção de objetos artesanais a partir de suas folhas, sementes (Queiroz \& Bianco, 2009) e raquis, além de servir como madeira para pequenas construções rurais. A planta é, portanto, uma fonte de renda para as comunidades ribeirinhas do estuário amazônico. Essa palmeira tem sido explorada para diferentes usos em seu ambiente natural, porém, seu potencial econômico baseia-se principalmente na utilização da polpa dos frutos e na extração de palmito e de óleo comestível.

A propagação das palmeiras se dá principalmente por sementes, sendo que a maioria apresenta germinação lenta e desuniforme, requerendo, em algumas espécies mais de 100 dias para germinar (Tomlinson, 1990; citado por Meerow \& Broschat, 2012). A emergência das sementes de palmeira é geralmente caracterizada por dificuldades que variam desde aspectos morfológicos até as peculiaridades fisiológicas do processo germinativo (Silva et al., 2009). Para a emergência e desenvolvimento inicial das plântulas é importante o uso de substratos que apresentem características facilitadoras desses processos, tais como porosidade e capacidade de retenção de água (Ferreira et al., 2009). Além disso, o substrato deve apresentar riqueza em nutrientes, $\mathrm{pH}$, estrutura e textura adequados, bem como não conter patógenos (Silva et al., 2001); outras características importantes são o baixo custo e a disponibilidade do substrato nas regiões de consumo.

Aliado ao fator substrato, a utilização de ambientes protegidos pode promover melhor desenvolvimento das plântulas, pois contribuem no controle da temperatura e da intensidade de radiação (Roweder et al., 2012), melhorando as condições para a germinação e emergência. Assim, os estudos em ambientes protegidos, como estufas agrícolas, viveiros de mudas e casas de vegetação climatizadas são de grande importância (Costa et al., 2012).
O baixo percentual de germinação e o crescimento lento e desuniforme apresentado pela maioria das espécies de palmeiras torna a propagação dessas espécies bastante complicada, sendo, portanto, necessários estudos que avaliem as melhores condições de desenvolvimento, tendo em vista a importância econômica dessas espécies. No caso da bacabeira, ainda são desconhecidas as condições ótimas para a emergência das sementes, bem como os substratos mais adequados para o desenvolvimento dessa palmeira, o que dificulta a inserção da espécie em sistemas de produção. Tendo em vista a importância social e o grande potencial econômico da bacabeira são necessários estudos básicos para subsidiar sua domesticação, em especial pesquisas que avaliem o potencial germinativo em ambientes que não sejam aqueles naturais da espécie. Com base nessas informações o objetivo do trabalho foi avaliar o efeito de diferentes substratos e ambientes na emergência e no desenvolvimento inicial da bacabeira.

\section{MATERIALE MÉTODOS}

O experimento foi conduzido no setor de Horticultura da Universidade Federal do Ceará ( $3^{\circ} 44^{\prime} \mathrm{S} ; 38^{\circ} 34^{\prime}$ W), de agosto a outubro de 2016. Os frutos de bacaba foram coletados de plantas adultas na área de produtor rural na cidade de Baião-PA $\left(2^{\circ} 47^{\prime} \mathrm{S} ; 49^{\circ} 40^{\prime} \mathrm{W}\right)$. Os frutos foram encaminhados para Fortaleza-CE, chegando $48 \mathrm{~h}$ após a coleta. Retirou-se a polpa dos frutos por meio imersão em água morna $\left(45^{\circ} \mathrm{C}\right)$ durante 20 minutos e, posteriormente, por maceração contra peneira (Queiroz, 2000).

Antes da aplicação dos tratamentos as sementes foram lavadas em água com solução de hipoclorito a $2 \%$ durante 10 minutos; em seguida, lavadas em água corrente e, posteriormente, colocadas sobre papel toalha para retirar o excesso de água. O teor de umidade das sementes foi determinado por meio do método da estufa à $105^{\circ} \mathrm{C} \pm 3^{\circ} \mathrm{C}$, por $24 \mathrm{~h}$ (Brasil, 2009), utilizando-se quatro repetições com 10 sementes cada. $\mathrm{O}$ teor de água obtido foi de $39,41 \%$.

O delineamento experimental utilizado foi inteiramente ao acaso, em esquema fatorial $5 \times 2$, sendo os fatores, cinco substratos: $\mathrm{S} 1$ = fibra de coco, S2 $=$ húmus de minhoca, $\mathrm{S} 3$ = fibra de coco + húmus de minhoca $(1: 1 \mathrm{v} / \mathrm{v}), \mathrm{S} 4=$ vermiculita e S5 = bagana de carnaúba peneirada; e, dois ambientes: A1 = casa de vegetação e A2 = sombreado (laboratório de sementes, 
sem controle de temperatura e umidade relativa do ar, com incidência de luz apenas nas laterais, ou seja, com sombreamento de cerca de $75 \%$, buscando simular o ambiente de germinação das sementes de bacabeira na floresta). Os dez tratamentos (5x2) tiveram quatro repetições e, cada parcela experimental foi composta por 50 sementes de bacabeira, empregando-se, no total, 2 mil sementes da espécie para a condução da pesquisa.

Os substratos foram umedecidos periodicamente e, as sementes foram colocadas a 1,5 cm de profundidade, em bandejas com dimensões de $35 \mathrm{~cm}$ de comprimento, $15 \mathrm{~cm}$ de largura e $10 \mathrm{~cm}$ de altura, perfuradas para drenagem do excesso de água.

Depois da aplicação dos tratamentos foram realizadas as seguintes avaliações:

a) Temperatura e umidade dos ambientes - foi mensurada periodicamente a temperatura $\left({ }^{\circ} \mathrm{C}\right)$ e a umidade relativa do ar $(\%)$ de cada ambiente, no horário compreendido entre 12 e $13 \mathrm{~h}$, considerado de altas temperaturas; para tanto utilizou-se o relógio termo-higrômetro modelo Minipa MT- $241^{\circledR}$.

b) Emergência - Aos 60 dias após a semeadura, avaliouse a emergência, considerando plântula emersa aquela que ultrapassou cerca de $1 \mathrm{~cm}$ do substrato, cujos resultados foram expressos em porcentagem de plântulas normais.

c) Tempo médio de emergência - avaliou-se o número de plântulas emergidas diariamente, até 60 dias após a semeadura, sendo o tempo calculado conforme adaptação da fórmula proposta por Edmond \& Drapala (1958):

$\mathrm{TME}=\mathrm{E} 1 / \mathrm{T} 1+\mathrm{E} 2 / \mathrm{T} 2+\ldots+\mathrm{En} / \mathrm{Tn}$

em que:

$\mathrm{TME}=$ tempo médio de emergência.

$\mathrm{E}_{1}, \mathrm{E}_{2}, \mathrm{E}_{\mathrm{n}}=$ número de plântulas normais emergidas na primeira contagem, na segunda contagem e na última contagem.

$\mathrm{T}_{1}, \mathrm{~T}_{2}, \mathrm{~T}_{\mathrm{n}}=$ tempo em dias da semeadura à primeira, à segunda e à última contagem.

d) Índice de velocidade de emergência - avaliou-se o número de plântulas emergidas diariamente, até 60 dias após a semeadura, sendo o índice calculado conforme a fórmula proposta por Maguire (1962):
$\mathrm{IVE}=\mathrm{E} 1 / \mathrm{N} 1+\mathrm{E} 2 / \mathrm{N} 2+\ldots+\mathrm{En} / \mathrm{Nn}$

em que:

IVE = índice de velocidade de emergência.

$\mathrm{E}_{1}, \mathrm{E}_{2}, \mathrm{E}_{\mathrm{n}}=$ número de plântulas normais computadas na primeira contagem, na segunda contagem e na última contagem.

$\mathrm{N}_{1}, \mathrm{~N}_{2}, \mathrm{~N}_{\mathrm{n}}=$ número de dias da semeadura à primeira, à segunda e à última contagem.

e) Comprimento da parte aérea - determinado com base na mensuração da região que se prende a semente, até a extremidade da parte aérea, avaliado 60 dias após a semeadura, cujos resultados foram expressos em $\mathrm{cm}$.

f) Comprimento da raiz principal - determinado com base na mensuração da região que se prende a semente, até a extremidade da raiz principal, avaliado 60 dias após a semeadura, cujos resultados foram expressos em $\mathrm{cm}$.

g) Massa seca da parte aérea e das raízes - retirouse 25 plântulas de cada repetição, após o desligamento das sementes, as quais foram separadas em parte aérea e raízes; e, logo após, foram colocadas em sacos de papel tipo kraft e levadas à estufa de circulação de ar a $70 \pm 2^{\circ} \mathrm{C}$ por 48 horas; em seguida, foram pesadas e os resultados expressos em $\mathrm{g}$.

Os dados obtidos foram submetidos à análise de variância pelo teste $\mathrm{F}$ e as médias comparadas pelo teste Scott-Knott a 5\% de probabilidade. As análises estatísticas foram realizadas por meio do programa de sistema de análise de variância - SISVAR ${ }^{\circledR}$ versão 5.3. (Ferreira, 2010).

\section{RESULTADOS E DISCUSSÃO}

O teor de água das sementes de bacabeira observado nesta pesquisa foi de 39,4\%. José et al. (2012), estudando a tolerância de sementes de bacabeira à dessecação, observaram que o teor de água de $39,9 \%$ foi o que alcançou maior germinação $(91,1 \%)$; desta forma, o resultado reforça a informação de que se trata de espécie com sementes recalcitrantes. As temperaturas e as umidades relativas dos diferentes ambientes foram: casa de vegetação $=38,9^{\circ} \mathrm{C}$ e $29,3 \%$ e sombreado $=$ $32,1^{\circ} \mathrm{C}$ e $39,1 \%$, respectivamente, indicando variação nas condições ambientais em que as sementes foram submetidas. 
Os resultados da análise de variância revelaram efeitos significativos da interação substratos vs. ambientes para as características analisadas, exceto no caso da emergência, do índice de velocidade de emergência e do comprimento da parte aérea. Isso significa que os substratos tiveram comportamentos distintos nos diferentes ambientes aos quais as sementes foram submetidas (Tabela 1).

A emergência das plântulas sofreu efeito significativo dos substratos (Figura 1); as médias de emergência oscilaram entre $74,3 \%$ e $94,5 \%$, com as menores médias sendo observadas no substrato bagana de carnaúba (74,3\%). A cera residual presente na bagana de carnaúba prejudicou, provavelmente, o acúmulo de água nesse substrato; as repetidas irrigações devem ter provocado a compactação do material e, consequentemente, a diminuição da aeração, influenciando assim a emergência das plântulas. Os demais substratos, com características de boa retenção de água, apresentaram emergência acima de $90 \%$, sendo os substratos húmus de minhoca $(94,3 \%)$ e vermiculita $(94,5 \%)$ os que apresentaram as maiores porcentagens de emergência; ambos os substratos têm como característica a alta capacidade de retenção e expansão em contato com a água, beneficiando, assim, a emergência das plântulas de bacabeira por manter a umidade alta no substrato e disponibilizar gradativamente a água para as sementes. De acordo com Afonso et al. (2012), diferentes materiais ou composições de substratos possuem variações em seus efeitos sobre a emergência das plântulas. BeckmannCavalcante et al. (2012) obtiveram com o substrato vermiculita a maior porcentagem de germinação de sementes das palmeiras juçara $(76,2 \%)$ e açaí $(61,1 \%)$.
Portanto, as plântulas de bacabeira podem ser propagadas em substratos que tenham características semelhantes às dos substratos húmus de minhoca e vermiculita.

Observa-se efeito significativo do substrato e do ambiente no índice de velocidade de emergência (Figuras 2 e 3 ). Os substratos húmus de minhoca $(1,21)$, fibra de coco + húmus de minhoca $(1,16)$ e vermiculita $(1,23)$ não diferiram significativamente entre si, apresentando as maiores médias de IVE; o substrato bagana de carnaúba $(0,83)$ foi o que apresentou menor média (Figura 2). A capacidade de reter água que os

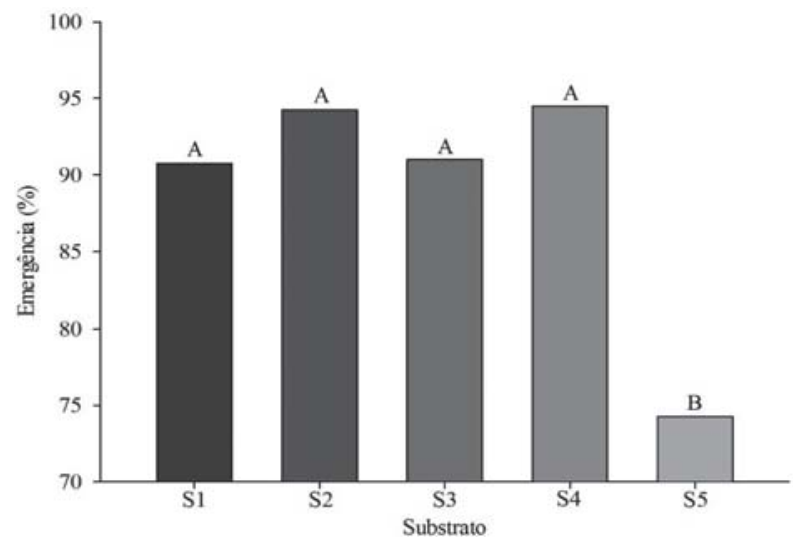

* Médias seguidas pela mesma letra maiúscula não diferem entre si pelo teste de Scott-Knott à $5 \%$ de probabilidade. S1: fibra de coco, $\mathrm{S} 2$ : húmus de minhoca, $\mathrm{S} 3$ : fibra de coco + húmus de minhoca $(1: 1 \mathrm{v} / \mathrm{v}), \mathrm{S} 4$ : vermiculita e S5: bagana de carnaúba.

Figura 1 - Emergência de plântulas de bacabeira propagadas em diferentes substratos, Fortaleza-CE 2016.

Tabela 1 - Resumo da análise de variância para emergência (E), tempo médio de emergência (TME), índice de velocidade de emergência (IVE), comprimento da parte aérea (CPA), comprimento da raiz principal (CR), massa seca da parte aérea (MSPA) e massa seca das raízes (MSR), avaliadas em sementes de bacabeira, em diferentes substratos e ambientes, Fortaleza-CE 2016

\begin{tabular}{lcccccccc}
\hline & \multicolumn{7}{c}{ Quadrado médio } \\
\cline { 2 - 8 } FV & GL & E & TME & IVE & CPA & CR & MSPA & MSR \\
\hline S & 4 & $564,8500^{* *}$ & $71,8351^{* *}$ & $0,2220^{* *}$ & $18,8961^{* *}$ & $58,6687^{* *}$ & $2,8159^{* *}$ & $1,0617^{* *}$ \\
A & 1 & $168,1000^{\text {ns }}$ & $100,2039^{* *}$ & $0,1729^{* *}$ & $1,3032^{*}$ & $6,7568^{* *}$ & $0,8165^{* *}$ & $0,6378^{* *}$ \\
S x A & 4 & $27,8500^{\text {ns }}$ & $6,8553^{* *}$ & $0,0110^{\text {ns }}$ & $0,5201^{\text {ns }}$ & $2,5885^{* *}$ & $0,8128^{* *}$ & $0,2250^{* *}$ \\
Erro & 30 & 83,3667 & 2,2914 & 0,0121 & 0,2089 & 0,6217 & 0,0439 & 0,0161 \\
CV $(\%)$ & & 10,26 & 3,63 & 10,05 & 6,12 & 7,74 & 7,21 & 8,33 \\
\hline
\end{tabular}

** Significativo à $1 \%$ de probabilidade pelo teste de Scott-Knott.

* Significativo à $5 \%$ de probabilidade pelo teste de Scott-Knott.

ns - não significativo. 


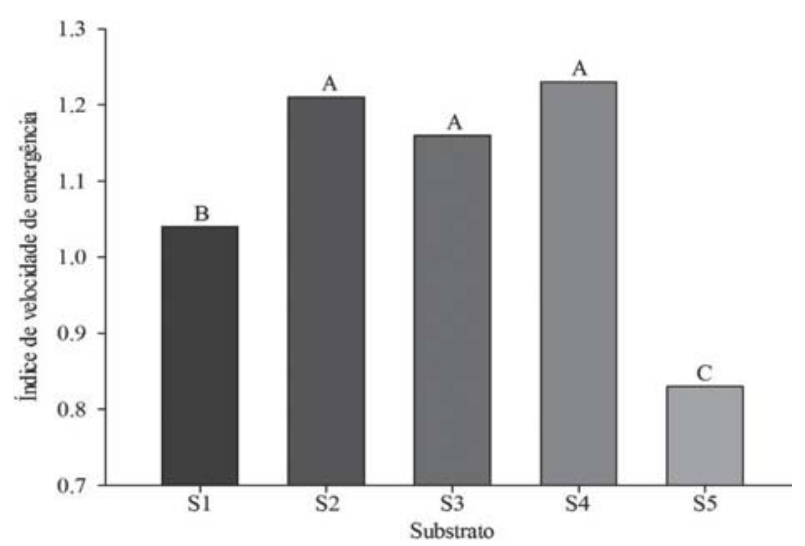

* Médias seguidas pela mesma letra maiúscula não diferem entre si pelo teste de Scott-Knott à $5 \%$ de probabilidade. S 1 : fibra de coco, S2: húmus de minhoca, S3: fibra de coco + húmus de minhoca $(1: 1 \mathrm{v} / \mathrm{v}), \mathrm{S} 4$ : vermiculita e $\mathrm{S} 5$ : bagana de carnaúba.

Figura 2 - Índice de velocidade de emergência de plântulas de bacabeira propagadas em diferentes substratos, Fortaleza-CE 2016.

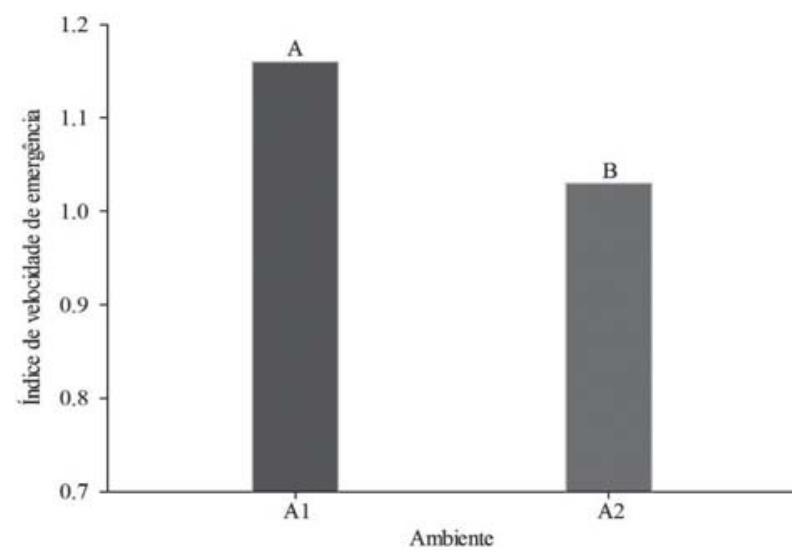

* Médias seguidas pela mesma letra maiúscula não diferem entre si pelo teste de Scott-Knott à $5 \%$ de probabilidade. A1: casa de vegetação e A2: sombreado.

Figura 3 - Índice de velocidade de emergência de plântulas de bacabeira propagadas em diferentes ambientes, Fortaleza-CE 2016.

diferentes substratos possuem influencia diretamente a umidade da semente e, com isso, pode afetar a velocidade de emergência das plântulas; no caso das sementes de bacabeira a umidade é fundamental, em virtude da manutenção da recalcitrância da semente dessa palmeira. Andrade et al. (1999), reavaliando o efeito de substratos e da temperatura na germinação de sementes de palmiteiro (Euterpe edulis Mart.), observaram que a vermiculita foi o substrato que proporcionou o maior IVE.

Com relação ao ambiente, observam-se maiores valores de IVE no ambiente casa de vegetação $(1,16)$, quando comparado ao ambiente sombreado $(1,03)$ (Figura 3). Resultado semelhante ao deste trabalho foi encontrado para a palmeira inajá (Maximiliana maripa (Aublet) Drude), que quando semeadas em ambiente de casa de vegetação apresentaram maiores índices de velocidade de emergência (Passos \& Yuyama, 2015). A alta temperatura observada no ambiente casa de vegetação $\left(38,9^{\circ} \mathrm{C}\right)$, estimulou, provavelmente, a emergência das plântulas de bacabeira; segundo Meerow \& Broschat (2012), as sementes de palmeiras requerem altas temperaturas para germinação mais rápida e uniforme e, consequentemente, maior IVE.

Desdobrando-se a interação ( $\mathrm{S}$ vs. A) observase na Tabela 2 o tempo médio de emergência (TME) das plântulas de bacabeira. Em ambos os ambientes, os substratos húmus de minhoca, fibra de coco + húmus de minhoca e vermiculita foram os que apresentaram menores TME. As diferentes características físicas dos substratos devem ter influenciado a velocidade de embebição das sementes e, consequentemente, afetado o TME. Avaliando o efeito do ambiente dentro do substrato para o TME pode-se observar que não houve diferença significativa no substrato húmus de minhoca; os demais substratos diferiram significativamente entre si, sendo o ambiente casa de vegetação o que proporcionou, sempre, os menores valores de TME. O crescimento das plantas pode refletir a habilidade de adaptação das espécies às condições de radiação do ambiente em que estão se desenvolvendo (Silva et al., 2007). O substrato vermiculita, associado ao ambiente casa de vegetação, proporcionou o menor tempo médio de emergência $(36,77)$. Oliveira et al. (2009), estudando a influência do tamanho da semente, de diferentes substratos e de tipos de ambientes na emergência de plântulas de carnaúba hospedeira (Copernicia hospita Martius), observaram que as sementes da palmeira propagadas em casa de vegetação apresentaram o menor tempo médio de emergência. Devido a vermiculita apresentar boa capacidade de retenção de água, esse substrato garantiu a manutenção da umidade das sementes, evitando sua dessecação e proporcionando rápido desenvolvimento das plântulas. 
Tabela 2 - Tempo médio de emergência (TME) e comprimento da raiz principal (CR) de plântulas de bacabeira propagadas em diferentes substratos e ambientes, Fortaleza-CE

\begin{tabular}{crr}
\hline \multirow{2}{*}{ Substrato } & \multicolumn{2}{c}{ Ambiente } \\
\cline { 2 - 3 } & \multicolumn{2}{c}{ A1 A2 } \\
\hline & Tempo médio de emergência (dias) \\
S1 & $42,02 \mathrm{bA}$ & $46,95 \mathrm{bB}$ \\
S2 & $39,31 \mathrm{aA}$ & $39,65 \mathrm{aA}$ \\
S3 & $38,51 \mathrm{aA}$ & $41,71 \mathrm{aB}$ \\
S4 & $36,77 \mathrm{aA}$ & $41,47 \mathrm{aB}$ \\
S5 & $44,12 \mathrm{bA}$ & $46,77 \mathrm{bB}$ \\
& Comprimento da raiz principal $(\mathrm{cm})$ \\
S1 & $10,77 \mathrm{bA}$ & $9,88 \mathrm{bA}$ \\
S2 & $8,44 \mathrm{cA}$ & $8,75 \mathrm{cA}$ \\
S3 & $10,61 \mathrm{bA}$ & $8,11 \mathrm{cB}$ \\
S4 & $15,16 \mathrm{aA}$ & $13,97 \mathrm{aB}$ \\
S5 & $8,00 \mathrm{cA}$ & $8,15 \mathrm{cA}$ \\
\hline
\end{tabular}

* Médias seguidas pela mesma letra, minúscula na coluna e maiúscula na linha, não diferem entre si pelo teste de Scott- Knott a $5 \%$ de probabilidade. S1: fibra de coco, S2: húmus de minhoca, S3: fibra de coco + húmus de minhoca $(1: 1 \mathrm{v} / \mathrm{v})$, S4: vermiculita, S5: bagana de carnaúba, A1: casa de vegetação e A2: sombreado.

Para o comprimento da raiz principal (Tabela 2) observa-se que nos ambientes casa de vegetação e sombreado, o substrato vermiculita $(15,16$ e $13,97 \mathrm{~cm})$ apresentou as maiores médias, diferindo estatisticamente dos demais substratos. Segundo Guedes et al. (2010), a vermiculita é um substrato que possui boa aeração, o que, aliado ao consumo mais eficiente das reservas presentes nas sementes, favorece o crescimento radicular, uma vez que nessa fase todo desenvolvimento das plântulas se deve à reserva das sementes. No ambiente casa de vegetação, o substrato bagana de carnaúba $(8,00 \mathrm{~cm})$ apresentou a menor média; a baixa capacidade de retenção de água observada neste substrato, associada a alta temperatura registrada no ambiente da casa de vegetação, prejudicou o desenvolvimento radicular das plântulas; no ambiente sombreado, o substrato fibra de coco + húmus de minhoca alcançou menor média $(8,11 \mathrm{~cm})$. Nos substratos fibra de coco e bagana de carnaúba, o ambiente casa de vegetação mostrou melhor resultado; não houve influência do ambiente nos demais substratos. Desse modo, o substrato vermiculita, associado ao ambiente casa de vegetação, mostrou maior valor médio para o comprimento da raiz principal. O ambiente casa de vegetação ofereceu luminosidade adequada para a parte aérea e, o substrato vermiculita, forneceu água e aeração suficientes para as raízes; com isso, a plântula se desenvolveu normalmente, o que culminou em maior CR.

As médias de comprimento da parte aérea (CPA) das plântulas de bacabeira estão nas Figuras 4 e 5. Os substratos húmus de minhoca $(8,91 \mathrm{~cm})$ e vermiculita $(8,84 \mathrm{~cm})$ foram os que apresentaram as maiores médias para CPA, diferindo estatisticamente dos demais substratos. De acordo com Oliveira et al. (2008), a boa capacidade de aeração, drenagem, retenção e disponibilidade de água apresentada pelos substratos influencia o início do crescimento da parte aérea das plântulas. Roweder et al. (2012), estudando o efeito de diferentes substratos e da ambiência na germinação e no desenvolvimento inicial de plântulas de cedro, constataram os maiores valores médios para CPA no substrato húmus de minhoca. Os substratos fibra de coco e fibra de coco + húmus de minhoca apresentaram médias de 6,19 e $7,84 \mathrm{~cm}$ respectivamente. O substrato bagana de carnaúba $(5,54 \mathrm{~cm})$ foi o que apresentou a menor média de CPA (Figura 4). Isso ocorreu, provavelmente, devido à menor capacidade de retenção de água do substrato bagana de carnaúba; de acordo com Sousa et al. (2014), a baixa capacidade de retenção de água dos substratos prejudica os eventos iniciais relacionados à germinação, influenciando dessa forma o comprimento da parte aérea.

O ambiente casa de vegetação $(7,64 \mathrm{~cm})$ foi superior ao ambiente sombreado $(7,28 \mathrm{~cm})$ para o comprimento da parte aérea (Figura 5). De acordo com Scalon et al. (2003), a eficiência do crescimento vegetal pode ser relacionada à habilidade de adaptação das plântulas às condições luminosas do ambiente. Esse fato foi observado no presente trabalho, uma vez que o ambiente casa de vegetação apresentou maior luminosidade, quando comparado ao ambiente sombreado.

Na Tabela 3 são apresentados os valores do desdobramento da interação ( $\mathrm{S} v s$. A) para a massa seca da parte aérea (MSPA) e massa seca das raízes (MSR) das plântulas de bacabeira. Observa-se que no ambiente casa de vegetação, todos os substratos diferiram estatisticamente entre si, sendo que o substrato vermiculita alcançou a maior média e o substrato fibra de coco apresentou a menor média de MSPA; no ambiente sombreado, os substratos húmus de minhoca e vermiculita atingiram os maiores valores médios e a bagana de carnaúba apresentou a menor média de MSPA. Silva 


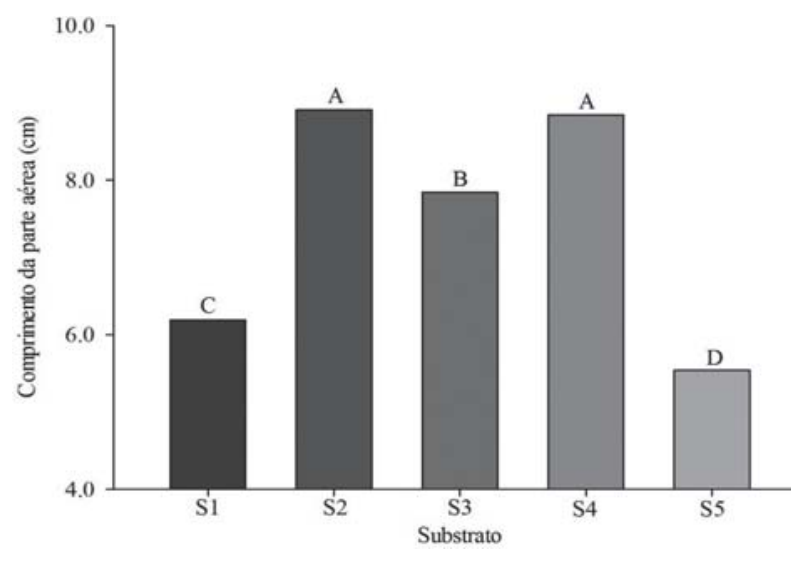

* Médias seguidas pela mesma letra maiúscula não diferem entre si pelo teste de Scott-Knott à $5 \%$ de probabilidade. S1: fibra de coco, $\mathrm{S} 2$ : húmus de minhoca, $\mathrm{S} 3$ : fibra de coco + húmus de minhoca $(1: 1 \mathrm{v} / \mathrm{v}), \mathrm{S} 4$ : vermiculita e S5: bagana de carnaúba.

Figura 4 - Comprimento da parte aérea de plântulas de bacabeira propagadas em diferentes substratos, Fortaleza-CE 2016.

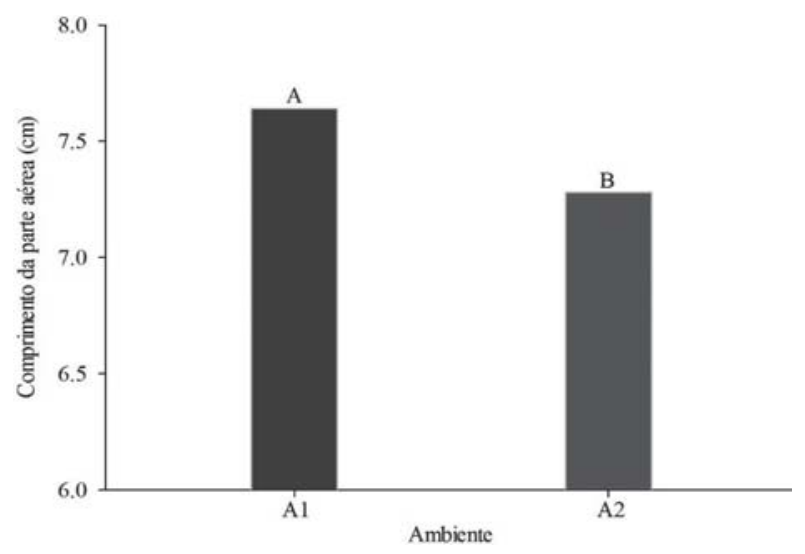

* Médias seguidas pela mesma letra maiúscula não diferem entre si pelo teste de Scott-Knott à $1 \%$ de probabilidade. A1: casa de vegetação e A2: sombreado.

Figura 5 - Comprimento da parte aérea de plântulas de bacabeira propagadas em diferentes ambientes, Fortaleza-CE 2016.

et al. (2017), avaliando o efeito do tamanho da semente e substratos na produção de mudas de açaí, observaram médias mais elevadas para massa seca da parte aérea em plantas que se desenvolveram em substrato com composto orgânico. Segundo Carneiro (1995), o húmus de minhoca tem propriedade de expansão e retenção de água em resposta às condições de umidade, auxiliando
Tabela 3 - Massa seca da parte aérea (MSPA) e massa seca das raízes (MSR) de plântulas de bacabeira propagadas em diferentes substratos e ambientes, Fortaleza-CE

\begin{tabular}{ccr}
\hline \multirow{2}{*}{ Substrato } & \multicolumn{2}{c}{ Ambiente } \\
\cline { 2 - 3 } & \multicolumn{2}{c}{ Massa seca da parte aérea $(\mathrm{g})$} \\
& $1,81 \mathrm{eB}$ & $2,47 \mathrm{cA}$ \\
S1 & $3,21 \mathrm{cA}$ & $3,29 \mathrm{aA}$ \\
S2 & $3,55 \mathrm{bA}$ & $2,79 \mathrm{bB}$ \\
S3 & $3,92 \mathrm{aA}$ & $3,16 \mathrm{aB}$ \\
S4 & $2,75 \mathrm{dA}$ & $2,10 \mathrm{~dB}$ \\
S5 & Massa seca das raízes $(\mathrm{g})$ \\
& $1,39 \mathrm{cA}$ & $1,27 \mathrm{bA}$ \\
S1 & $1,04 \mathrm{dA}$ & $1,22 \mathrm{bA}$ \\
S2 & $1,89 \mathrm{bA}$ & $1,27 \mathrm{bB}$ \\
S3 & $2,38 \mathrm{aA}$ & $1,82 \mathrm{aB}$ \\
S4 & $1,55 \mathrm{cA}$ & $1,40 \mathrm{bA}$ \\
S5 &
\end{tabular}

* Médias seguidas pela mesma letra, minúscula na coluna e maiúscula na linha, não diferem entre si pelo teste de Scott- Knott a 5\% de probabilidade. S1: fibra de coco, S2: húmus de minhoca, S3: fibra de coco + húmus de minhoca (1:1 v/v), S4: vermiculita, S5: bagana de carnaúba, A1: casa de vegetação e A2: sombreado.

na adequada manutenção da estrutura dos substratos; além disso, substratos bem estruturados promovem melhor crescimento vegetal. A determinação da massa seca de plântulas é uma das maneiras de avaliar o seu crescimento com precisão; a transferência de matéria seca dos tecidos de reserva para o eixo embrionário indica que plântulas com maior massa seca são consideradas mais vigorosas (Nakagawa, 1999). Nos substratos fibra de coco + húmus de minhoca, vermiculita e bagana de carnaúba, o ambiente casa de vegetação proporcionou maiores médias, quando comparado ao sombreado; no substrato fibra de coco, o ambiente sombreado possibilitou maiores médias; o substrato húmus de minhoca não foi influenciado pelo ambiente. O maior valor médio para MSPA foi observado na interação entre o substrato vermiculita $(3,92$ g) e o ambiente casa de vegetação. No ambiente casa de vegetação as plântulas apresentaram, provavelmente, maior eficiência no aproveitamento da incidência luminosa, promovendo maior crescimento e, portanto, maior acúmulo de MSPA. Costa (2018), avaliando o crescimento inicial do açaizeiro, observou aumento da produção de biomassa nas plantas cultivadas em estufa agrícola.

A massa seca das raízes (MSR) é apresentada na Tabela 3. No ambiente casa de vegetação, o substrato vermiculita produziu a maior média; no ambiente sombreado os substratos fibra de coco, húmus de 
minhoca, fibra de coco + húmus de minhoca e bagana de carnaúba não diferiram estatisticamente entre si, apresentando médias inferiores ao substrato vermiculita. Iossi et al. (2003), avaliando o efeito de substratos e temperaturas na germinação de sementes de tamareiraanã (Phoenix roebelenii O'Brien), uma palmeira ornamental, observaram menor valor de massa seca das raízes no substrato vermiculita, resultado que difere do observado neste trabalho.

Comparando o efeito do ambiente dentro de cada substrato, observa-se que fibra de coco + húmus de minhoca e vermiculita alcançaram maiores médias no ambiente casa de vegetação; já nos substratos fibra de coco, húmus de minhoca e bagana de carnaúba não houve diferença estatística. Pode-se inferir que aqueles substratos com melhor capacidade de aeração, drenagem e retenção de água proporcionaram melhor formação do sistema radicular e, consequentemente, maior MSR. A combinação do substrato vermiculita $(2,38 \mathrm{~g})$ com o ambiente casa de vegetação promoveu a maior média para MSR. Gama et al. (2010), avaliando temperaturas e substratos para determinar a germinação e o vigor de sementes de açaí (Euterpe oleracea Mart.) observaram maiores valores para massa seca de plântulas (massa seca da parte aérea e das raízes) no substrato vermiculita à $35^{\circ} \mathrm{C}$.

\section{CONCLUSÕES}

Nas condições em que se desenvolveu o experimento pode-se afirmar que os substratos húmus de minhoca e vermiculita, são os mais indicados para a emergência e o desenvolvimento inicial da bacabeira.

O ambiente casa de vegetação é o mais indicado para a propagação e desenvolvimento inicial da bacabeira.

\section{AGRADECIMENTOS}

À Coordenação de Aperfeiçoamento de Pessoal de Nível Superior (Capes) e à Fundação Cearense de Apoio ao Desenvolvimento Científico e Tecnológico (Funcap), pela concessão de bolsas de estudos.

\section{LITERATURA CITADA}

AFONSO, M.V.; MARTINAZZO, E.G.; AUMONDE, T.Z.; VILLELA, F.A. Composição do substrato, vigor e parâmetros fisiológicos de mudas de timbaúva (Enterolobium contortisiliquum (Vell.) Morong). Revista Árvore, v.36, n.6, p.10191026, 2012.
ANDRADE, A.C.S.; LOUREIRO, M.B.; SOUZA, A.D.O.; RAMOS, F.N.; CRUZ, A.P.M. Reavaliação do efeito do substrato e da temperatura na germinação de sementes de palmiteiro (Euterpe edulis Mart.). Revista Árvore, v.23, n.3, p.279-283, 1999.

BECKMANN-CAVALCANTE, M.Z.; PIVETTA, K.F.L; ILHA, L.L.; TAKANE, R.J. Temperatura, escarificação mecânica e substrato na germinação de sementes das palmeiras juçara e açaí. Revista Brasileira de Ciências Agrárias, v.7, n.4, p.569-573, 2012.

BRASIL. Ministério da Agricultura, Pecuária e Abastecimento. Regras para análise de sementes. Brasília: Mapa/ACS, 2009. 399p.

CARneiro, J.G.A. Produção e controle de qualidade de mudas florestais. Curitiba: UFPR/FUPEF; Campos: UNEF, 1995.451p.

CAVALCANTE, P.B. Frutas comestíveis na Amazônia. 7. ed. Belém: Museu Paraense Emílio Goeldi, 2010.282p.

COSTA, E.; FERREIRA, A.F.A.; SILVA, P.N.L.; NARDELLI, E.M.V. Diferentes composições de substratos e ambientes protegidos na formação de mudas de pé-franco de tamarindeiro. Revista Brasileira de Fruticultura, v.34, n.4, p.1189$1198,2012$.

COSTA, C.A.S. Biometria de sementes, morfologia da germinação e crescimento inicial de cinco Arecaceae. Dissertação (Mestrado em Agronomia-Fitotecnia) - Fortaleza, CE: UFC, 2018.117p.

EDMOND, J.B.; DRAPALA, W.J. The effects of temperature, sand and soil, and acetone on germination of okra seed. Proceedings of the American Society Horticutural Science, v.71, n.2, p.428-434, 1958.

FERREIRA, M.G.R.; ROCHA, R.B.; GONCALVES, E.P.; ALVES, E.U.; RIBEIRO, G.D. Influência do substrato no crescimento de mudas de cupuaçu. Acta Scientiarum. Agronomy, v.31, n.4, p.677681, 2009.

FERREIRA, D.F. SISVAR ${ }^{\circledR}$ : Sistema de análise de variância para dados balanceados, versão 5.3. Lavras-MG: DEX/UFLA, 2010. (Software estatístico). 
GAMA, J.S.N.; MONTE, D.M.O.; ALVES, E.U.; BRUNO, R.L.A.; JÚNIOR, J.M.B. Temperaturas e substratos para germinação e vigor de sementes de Euterpe oleracea Mart. Revista Ciência Agronômica, v.41, n.4, p.664-670, 2010.

GUEDES, R.S.; ALVES, E.U.; GONCALVES, E.P.; BRAGA JUNIOR, J.M.; VIANA, J.S.; COLARES, P.N.Q. Substratos e temperaturas para testes de germinação e vigor de sementes de Amburana cearensis (Allemão) A.C. Smith. Revista Árvore, v.34, n.1, p.57-64, 2010.

IOSSI, E.; SADER, R.; PIVETTA, K.F.L.; BARBOSA, J.C. Efeitos de substratos e temperaturas na germinação de sementes de tamareira-anã (Phoenix roebelenii O'Brien). Revista Brasileira de Sementes, v.25, n.2, p.63-69, 2003.

JOSÉ, A.C.; ERASMO, E.A.L.; COUTINHO, A.B. Germinação e tolerância à dessecação de sementes de bacaba (Oenocarpus bacaba Mart.). Revista Brasileira de Sementes, v.34, n.4, p.651-657, 2012.

MAGUIRE, J.D. Speed of germination aid in selection and evaluation for seedling emergence and vigor. Crop Science, v.2, n.1, p.176-177, 1962.

MEEROW, A.W.; BRoschat, T.K. Palm seed germination. Gainesville: Institute of Food and Agricultural Sciences, University of Florida Cooperative Extension Service, 2012. Boletim 274. Disponível em: http://edis.ifas.ufl.edu/ pdffiles/EP/EP23800.pdf (acessado em 19 de fevereiro de 2018).

NAKAGAWA, J. Testes de vigor baseados no desempenho das plântulas. In: KRZYZANOSKI, F.C.; VIEIRA, R.D.; FRANÇA NETO, J.B. (Ed.).

Vigor de sementes: conceitos e testes. Londrina: ABRATES, 1999. p.2-13.

OLIVEIRA, R.B.; LIMA, J.S.S.; SOUZA, C.A.M.; SILVA, S.A.; MARTINS FILHO, S. Produção de mudas de essências florestais em diferentes substratos e acompanhamento do desenvolvimento em campo. Ciência e Agrotecnologia, v.32, n.1, p.122-128, 2008.
OLIVEIRA, A.B.; MEDEIROS FILHO, S.; BEZERRA, A.M.E.; BRUNO, R.L.A. Emergência de plântulas de Copernicia hospita Martius em função do tamanho da semente, do substrato e do ambiente. Revista Brasileira de Sementes, v.31, n.1, p.281-287, 2009.

PASSOS, M.A.B.; YUYAMA, K. Influência do período de armazenamento e do ambiente na emergência de plântulas de inajá em Boa Vista, Roraima. Biota Amazônia, v.5, n.1, p.79-82, 2015.

QUEIROZ, J.A.L. Germinação de sementes de bacaba (Oenocarpus bacaba Mart.) nas condições do estado do Amapá. Macapá: Embrapa Amapá. 3p. (Embrapa Amapá. Comunicado técnico, 32), 2000 .

QUEIROZ, M.S.M.; BIANCO, R. Morfologia e desenvolvimento germinativo de Oenocarpus bacaba Mart. (arecaceae) da Amazônia Ocidental. Revista Árvore, v.33, n.6, p.10371042, 2009.

ROWEDER, C.; NASCIMENTO, M.S.; SILVA, J.B. Uso de diferentes substratos e ambiência na germinação e desenvolvimento inicial de plântulas de cedro. Pesquisa Aplicada \& Agrotecnologia, v.5, n.1, p.27-46, 2012.

SCALON, S.P.Q.; MUSSURY, R.M.; RIGONI, M.R.; SCALON FILHO, H. Crescimento inicial de mudas de Bombacopsis glabra (Pasq.) A. Robyns sob condição de sombreamento.

Revista Árvore, v.27, n.6, p.753-758, 2003.

SILVA, R.P.D.; PEIXOTO, J.R.; JUNQUEIRA, N.T.V. Influência de diversos substratos no desenvolvimento de mudas de maracujazeiro azedo (Passiflora edulis Sims f. flavicarpa DEG). Revista Brasileira de

Fruticultura, v.23, n.2, p.377-381, 2001.

SILVA, R.R.; FREITAS, G.A.; SIEBENEICHLERR, S.C.; MATA, J.F.; CHAGAS, J.F.R.

Desenvolvimento inicial de plântulas de Theobroma grandiflorum (Willd. ex Spreng.) Schum. sob influência de sombreamento.

Revista Acta Amazônica, v. 37, n.3, p.365370, 2007. 
SILVA, R.A.M.; MOTA, M.G.C.; FARIAS NETO, J.T. Emergência e crescimento de plântulas de bacabi (Oenocarpus mapora Karsten) e bacaba (Oenocarpus distichus Mart.) e estimativas de parâmetros genéticos. Revista Acta Amazônica, v.39, n.3, p. 601-608, 2009.

SILVA, A.C.D.; SMIDERLE, O.J.; OLIVEIRA, J.M.F.; SILVA, T.J. Tamanho da semente e substratos na produção de mudas de açaí. Advances in Forestry Science, v.4, n.4, p.151-156, 2017.
SOUSA, N.A.; SILVA, K.B.; OLIVEIRA, A.N.P.; AGUIAR, V.A.; PINTO, M.S.C. Emergência e crescimento inicial de plântulas de Caesalpinia pulcherrima (L.) Swartz sob diferentes substratos. Revista Agrotec, v. 35, n.1, p. 106-112, 2014.

TOMLINSON, P.B. The structural biology of palms. Oxford: Clarendon Press, 1990. 460p.

Recebido para publicação em 03/04/2018 e aprovado em 30/06/2018. 